\title{
Verification of the Effect of Raw Materials Mill Dust on Soil Stabilization: An Experimental Study
}

\author{
Fatima Alsaleh $^{\text {* }}$, Feras Al Adday ${ }^{2}$, Ahmed Al-Abu Hussein ${ }^{1}$ \\ ${ }^{1}$ Department of Transportation Engineering, Faculty of Civil Engineering, University of Aleppo, \\ ${ }^{2}$ Middle East University, Amman, Jordan \\ Received: 26/07/2020 \\ Accepted: 21/10/2020 \\ Published: 20/03/2021
}

\begin{abstract}
Cement plants produce large quantities of dust, which is an important source of pollution. Among these pollutants is raw materials mill dust (RMMD), it is a dust produced during the grinding of raw materials. RMMD differs in chemical composition from cement kiln dust (CKD), where CKD is a by-product that collects in the electrostatic filters of a cement kiln. A lot of studies have been done around the world to find effective ways to recycle CKD and use it again in soil stabilization to avoid the failure of the entire pavement in the future as well as an economical and environmental solution, while there is a dearth of research done on RMMD. In this study, the performance of a weak subgrade for one of the sites in Aleppo city was examined, where its physical and mechanical properties (plasticity index, maximum dry density, optimum water content, and California bearing ratio (CBR)), were determined. Then RMMD was added to the subgrade samples according to five ratios $0,5,10,15$, and $20 \%$ of the dry weight of the soil. The research concluded that adding the RMMD to the weak subgrade by $20 \%$ of its dry weight is the optimal ratio, improved its performance, as the plasticity index decreased by $13 \%$, and the CBR increased up to $63 \%$. Thus, the bearing capacity increases, it saves costs and reduces future pavement maintenance.
\end{abstract}

Keywords: Soil Stabilization, Weak Soil, Mill Dust, Chemical additive

\section{Introduction}

The great growth in modern buildings imposed the need for lands with good bearing capacity to safely withstand high pressures [1]. One of the important issues facing the pavement engineer is to provide economically viable layer thicknesses that are compatible with the site's soil characteristics [2,3]. The general case is the lack of alternative design solutions to avoid weak soils, hence it is necessary to search for low-cost experimental alternatives $[4,5]$. The weak soil has the high compressibility, poor shear strength, high ratio of moisture, low workability, which produces extra settlements of soil, and this makes the construction process on such soils a high probability issue [6]. For road pavements, soil properties have a major influence in determining the thickness of the layers above [7]. Thus, road performance and service are greatly influenced by the stability and stiffness of the subgrade $[8,9]$. Consequently, these soil must be stabilized or treated to increase in its geotechnical characteristics. the term soil stabilization is a technique in which weak soil properties are improved to fulfil its functions (operational conditions of the road and the subsequent volumetric changes of soil) as the foundation for the structures based on it $[10,11,12,13]$. There are two techniques that are widely used for soil stabilization [14]. The first method is a mechanical method in which the bearing capacity is enhanced by compaction of the soil to a sufficient degree, or by means of piles or application of an external load on the soil or the use of good drainage of water, or stone columns $[15,16]$. The second technique is chemical stabilization of soil by a chemical reaction between weak soils and the added active substance [17, 18]. Among these materials are lime, gypsum, cement, asphalt, resin, fly ash, and other materials such as industrial or natural wastes such as the CKD and rice husk ash [15, 19, 20, 21, 22, and 23]. The common soil additives are lime and cement (traditional stabilizers) [24]. RMMD is of great importance in the field of civil engineering and its projects, and one of these uses is to improve weak soils. The flying dust is captured and collected from the raw material mill of the cement factory in Hama, Syria through two types of filters, Electrostatic and Baghouse Filters as well as for the dust flying throughout the entire manufacturing process of cement.

RMMD has been chosen as a weak soil stabilizer for several reasons, the most important of which is its large quantities and it is being a completely new material in this topic of soil stabilization in road pavement. The fact that the total quantity of the electric filter of the raw material mill is large when compared to the Baghouse filter, the research has focused on studying its effect on soil performance.

Corresponding author: Fatima Alsaleh, Department of Transportation Engineering, Faculty of Civil Engineering, University of Aleppo. Email: falkhalil@meu.edu.jo 


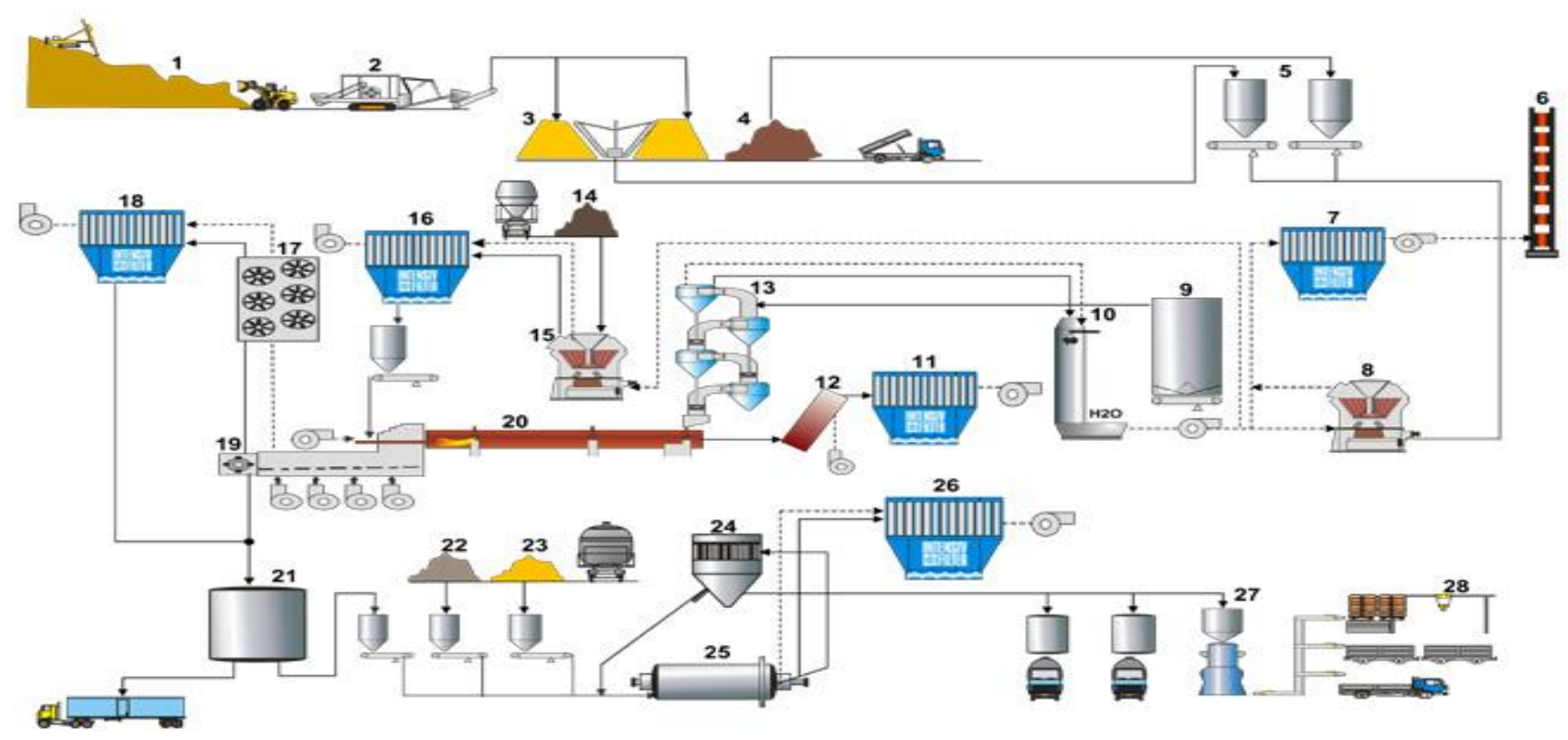

Figure 1: shows the parts of the cement factory, with electrical and Baghouse filters [27]

1- Quarries, 2- Crushers, 3- The homogenizing process, 4- The assembly process, 5- Feed silos of the raw material mill, 6- The main chimney, 7- Electric and Baghouse filters, 8- The raw material mill, 9- Raw material feeding silos, 10- gas temperature adjustment tower, 11- filters, 12- mixing chambers, 13- preheating tower (spiral), 14- raw coal, 15- coal mill, 16- filters, 17- tube cooler, 18-Electrical and Baghouse filters, 19- clinker cooler, 20- rotary kiln, 21 - clinker silos, 22- gypsum / plaster, 23- assorted metals, 24- sorters, 25- cement mill (finishing), 26- filters, 27- packaging 28- Loading and transport platform.

It should be noted that their physical and chemical properties between them are similar. Engineers strive for low-cost alternatives while maintaining appropriate performance, as materials with good specifications require high cost $[25,26]$. Figure 1 shows the parts of the Hama Cement Factory and the location of the electrical filter for the raw materials mill [27].

\section{Methodology}

Improving the performance of the subgrade by using RMMD as an additive to their structure was investigated, by studying the effect of adding RMMD on its physical and mechanical properties.

\subsection{Materials used}

Subgrade materials: Soil samples from one of the sites near the city of Aleppo were brought to the laboratory, where the required quantity was taken at a depth exceeding $50 \mathrm{~cm}$. A grain size analysis, soil classification, the optimum moisture content (OMC), shear resistance, and CBR were carried out. Table 1 shows the characteristics of the subgrade soil. Figure 2 shows a grain size analysis.

RMMD: It is a by-product material that is generally produced when grinding raw materials in the cement factory, the city of Hama, Syria. It has been added to soil samples according to 0,5 , 10,15 , and $20 \%$ of the dry weight of the soil. Regarding the chemical composition of RMMD, which was adopted as an additive to soil samples, it is shown in table 2, and table 3 shows its physical properties. There is a difference in the chemical composition of RMMD and CKD, and this has been proven by laboratory experiments, but there is a percentage of up to $48.3 \%$ of Cao that is somewhat close to the composition of CKD.

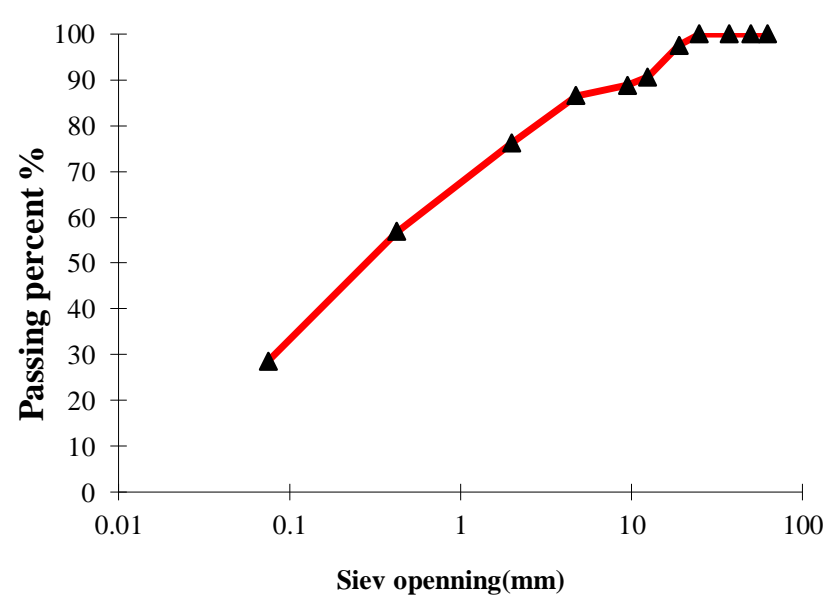

Figure 2: The soil gradation 
Table 1: Subgrade properties

\begin{tabular}{|c|c|c|}
\hline \multicolumn{2}{|l|}{ Properties } & \multirow{2}{*}{$\begin{array}{l}\text { Value } \\
28.6 \%\end{array}$} \\
\hline \multirow{3}{*}{$\begin{array}{l}\text { Grain Size } \\
\text { Analysis }\end{array}$} & Clay and silt $\%$ & \\
\hline & Sand $\%$ & $57.88 \%$ \\
\hline & Gravel\% & $13.52 \%$ \\
\hline \multirow{3}{*}{$\begin{array}{l}\text { Atterberg } \\
\text { Limits }\end{array}$} & $\begin{array}{l}\text { LL\%, liquid limit, } \\
\text { ASTM D } 4318\end{array}$ & 42 \\
\hline & $\begin{array}{l}\text { PL\% ,plasticity limit, } \\
\text { ASTM D } 4318\end{array}$ & 23 \\
\hline & PI\% (plasticity index) & 19 \\
\hline \multirow{2}{*}{$\begin{array}{l}\text { Modified } \\
\text { Proctor }\end{array}$} & $\operatorname{MDD}\left(\mathrm{gr} / \mathrm{cm}^{3}\right)$ ASTM D 698 & 1.72 \\
\hline & OMC \%, ASTM D 698 & 17.8 \\
\hline \multirow{2}{*}{$\begin{array}{l}\text { Soil } \\
\text { Classification }\end{array}$} & USCS, ASTM D 2487 & $\mathrm{SC}$ \\
\hline & AASHTO & A-2-7 \\
\hline \multicolumn{2}{|c|}{ CBR, ASTM D1883-05 } & $10.5 \%$ \\
\hline
\end{tabular}

Table 2: Chemical composition of RMMD

\begin{tabular}{cc}
\hline Composition & percent \\
\hline $\mathrm{PF}$ & 38.47 \\
\hline $\mathrm{SiO}_{2}$ & 7.47 \\
\hline $\mathrm{Al}_{2} \mathrm{O}_{3}$ & 2.65 \\
\hline $\mathrm{Fe}_{2} \mathrm{O}_{3}$ & 1.42 \\
\hline $\mathrm{MgO}$ & 1.48 \\
\hline $\mathrm{CaO}$ & 48.30 \\
\hline Total & 99.78 \\
\hline L.S.F & 193.51 \\
\hline S.M & 1.84 \\
\hline A.M & 1.86 \\
\hline Table3: Physical properties of RMMD \\
\hline Properties & Value \\
\hline Specific gravity, ASTM D 854 & 2.69 \\
\hline Specific surface (cm ${ }^{2} /$ gr) & 7812 \\
\hline Moisture \%, ASTM D 698 & 0.7 \\
\hline
\end{tabular}

\subsection{Main processes in the operating line of the cement industry} Crushing and mixing of raw materials:

Raw materials of limestone, silicates, clays and surface dust are crushed by milling mechanisms, then sifted and transported, to be stored as piles in open or covered areas [28].

Milling: Raw materials are introduced into a rotary dryer (in case the moisture is more than a certain percentage), where they are dried by hot air, then the raw materials are crushed in raw materials mills and transferred to pre-mixing storage silos, where they become homogeneous through compacting and drawing process, then the homogeneous raw materials are transferred from storage silos or other types from pre-mixing storage places to mixing places. The process of blending is $30 \%$ of clay, and $70 \%$ of limestone [28]
Oven and coolant: The homogeneous raw materials are pulled from the bottom of the storage silo into the feed slot of a multi-stage primary heating tower, and the tower may reach a height of $280 \mathrm{~m}$. Natural gas or diesel oil is used as a source of heat energy, and hot air from clinker cooling is used as an additional source of heat. The kiln is tilted slightly on the horizontal plane to allow a slow movement of solids down, so the distance is cut to the feed hole at the top of the oven to the lower end (combustion) where high-temperature combustion gases are generated in a period of 1 to 3 hours, while Combustion gases move upward in the current opposite to the movement of solids. The hot combustion gases heat the raw materials at the oven feed slot and provide calcium carbonate [28][29].

Final milling and packing: The clinker is transported to special mills, where the gypsum is added to it and the product is packed in bags to be exported and marketed [28].

\section{Results and discussion \\ 3.1 Plasticity characteristics ( LL, PL, PI)}

The effects of adding RMMD on LL, PL, and PI of soil are shown in Figure 3. The LL and PL decline with the addition of RMMD. This may be attributed to Cationic interchange of soil units with calcium ions which leads to drop LL because of suppression of flocculated clay clusters (this decreases the soil's attraction to water) [30,31], which, in turn, decreases in the PI of subgrade soil. A decrease in PI is a clear indication of improvement of soil physical properties as it increases workability [21]. The best PI decrease was reached at $20 \%$ RMMD, the largest decrease in PI was at 20\% RMMD, dropping from 19 for subgrade soils to 15 for stabilized soil. In this regard, a relationship between the PI and the percentages of RMMD for the subgrade soil can be presented, as shown in Figure 4.

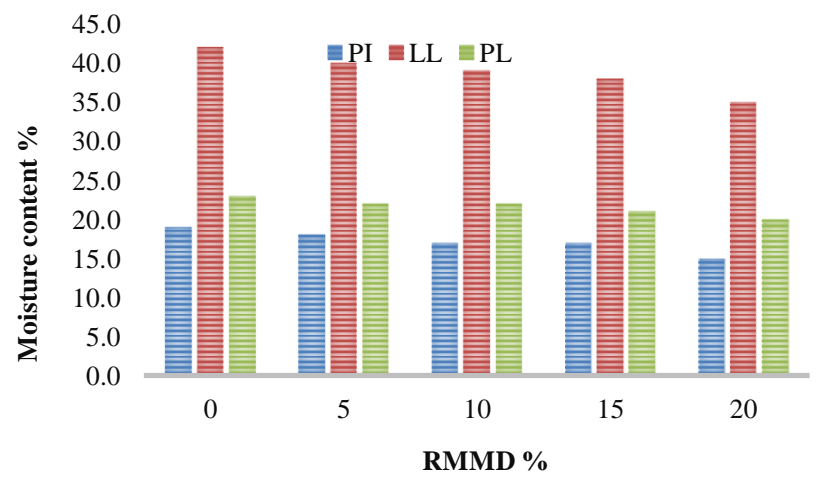

Figure 3: LL, PL, and PI changes versus RMMD \%

\subsection{Compaction characteristics (MDD, OMC)}

Figure 5 shows the general behavior of the subgrade soil, a gradual increase in the moisture content leads to increase the dry density up to maximum value, and then begins to decrease, and this is true for all RMMD ratios. OMC and MDD can be inferred for each addition of RMMD, Figure 6, 7 illustrate the relationship between the RMMD\% and OMC and MDD. An increase in MDD value was observed, and this is an indication of improved subgrade characteristics. The mechanism of the increase can be explained by the effect of both the fineness of the RMMD and specific surface of the RMMD and flocculation. The more finegrained of RMMD was able to fill larger spaces of soil whereas 
the higher specific surface of the RMMD to the soil encouraged MDD increase.

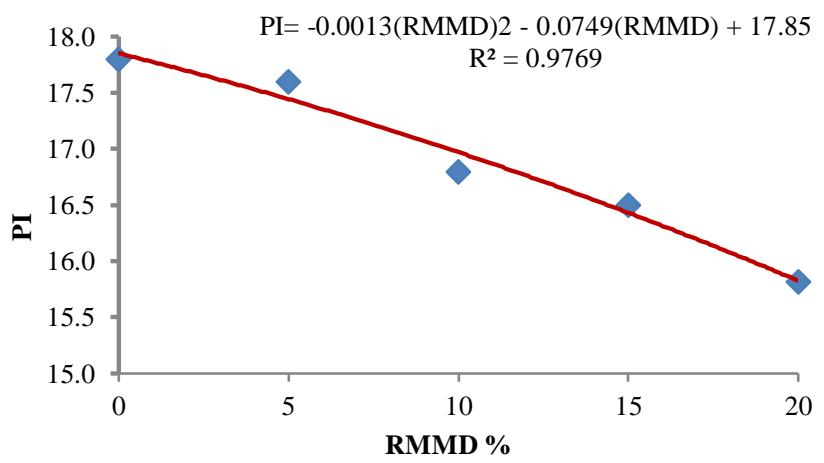

Figure 4: The relationship between the PI and RMMD \%

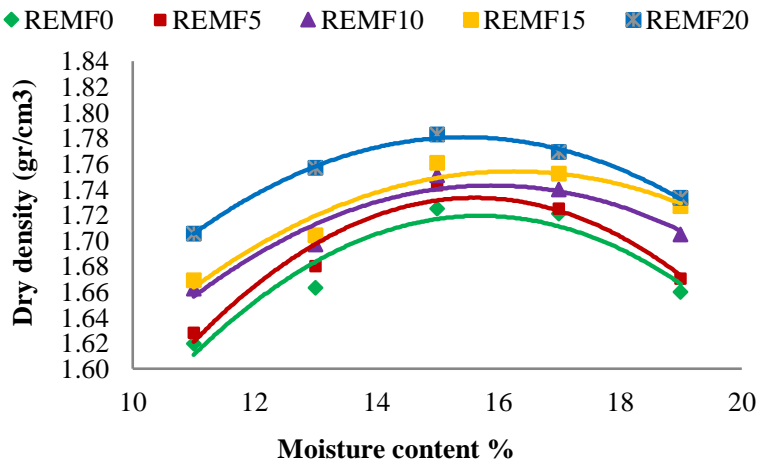

Figure 5: variations of dry density of subgrade soil according to the moisture content and RMMD\%

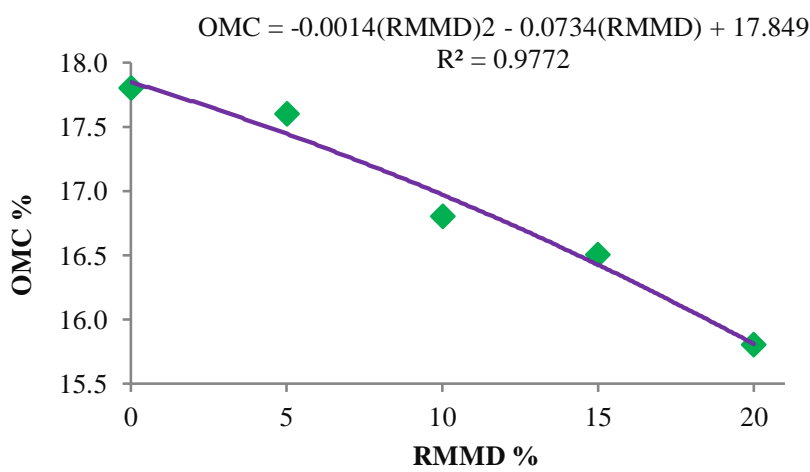

Figure 6: OMC \% according to the RMMD\%

\subsection{Mechanical properties (CBR)}

The CBR test is performed to calculate the bearing capacity of the subgrade or base course of highway pavement [32, 33].The CBR experiment was conducted with consideration of the OMC corresponding to the MDD for each of the samples $(0,5,10,15$, and $20 \%$ of RMMD). The samples were submerged in water for 7 days to suit the most dangerous situation. The CBR value have been increased $64 \%$ at adding 20\% of RDDM as shown in Figure 8. This indicates that increasing the percentage of RMMD leads to an increase in the bearing capacity of the soil, as different studies have shown that the creation of calcium hydroxide $(\mathrm{Ca}(\mathrm{OH}) 2)$ produced during the process of hydration of RMMD with water, this hydrate compound absorbed by the clay unites help to stabilize flocculated fine clay, as a result the adjustment of the clay microstructure has been occurred [21].

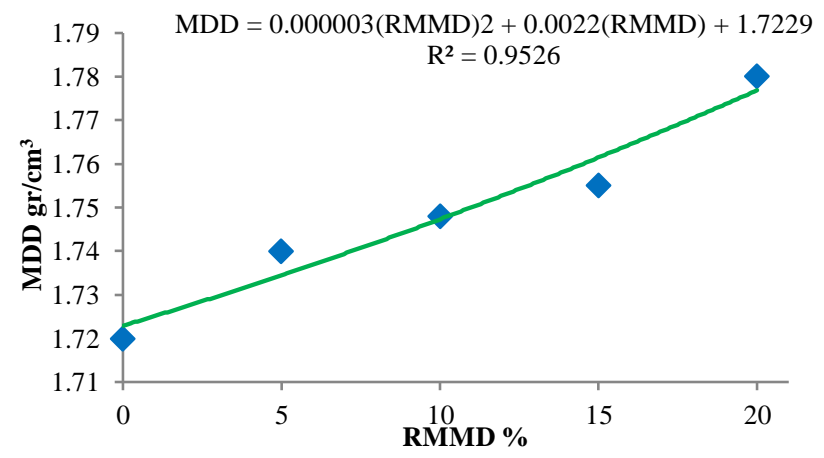

Figure 7: MDD according to the RMMD\%

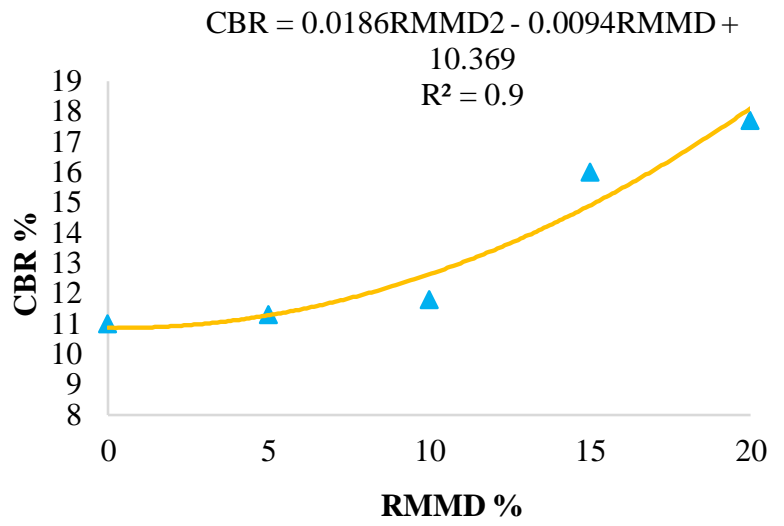

Figure 8: CBR according to the RMMD\%

Increase in the CBR of modified samples by the RMD considered a sustainable solution to the problem of solid waste harmful to the environment $[34,35]$.

\section{Conclusion}

Based on the investigations carried out in this research, RMMD can be considered a soil stabilizer, as its use improves the mechanical and physical properties of subgrade soil. The CBR value increased up to $63 \%$ when adding $20 \%$ of the RMMD compared to the reference samples ( $0 \%$ of the RMMD). The plasticity index of the soil decreased by $13 \%$ when adding $20 \%$ of RMMD. Furthermore, MDD increases with an increase RMMD ratio, and the OMC value decreases as the RMMD ratio increases. In addition to the above, the use of RMMD in soil stabilization constitutes a new scientific start for researchers to explore other soil properties. It is also considered sustainable sources of low-cost additives (reducing the thickness of road layers) and using these materials in soil stabilization will preserve the environment from harmful effects. 


\section{Aknowledgment}

The researchers thank very much to the Faculty of Civil Engineering at the University of Aleppo and Hama Cement Factory for their support in carrying out the laboratory experiments for this work. The authors are grateful to the Middle East University, Amman, Jordan for the financial support granted to cover the publication fee of this research article.

\section{Ethical issue}

Authors are aware of, and comply with, best practice in publication ethics specifically with regard to authorship (avoidance of guest authorship), dual submission, and manipulation of figures, competing interests and compliance with policies on research ethics. Authors adhere to publication requirements that submitted work is original and has not been published elsewhere in any language.

\section{Competing interests}

The authors declare that there is no conflict of interest that would prejudice the impartiality of this scientific work.

\section{Authors' contribution}

All authors of this study have a complete contribution for data collection, data analyses and manuscript writing.

\section{References}

[1] T. N. Dave, D. Patel, G. Saiyad, and N. Patolia., 2020. Use of Polypropylene Fibres for Cohesive Soil Stabilization. Lect. Notes Civ. Eng., vol. 56, no. August, pp. 409-417, 2020.

[2] Coudert, e., paris, m., deneele, d., russo, g., \& tarantino, a. (2019). Use of alkali activated high-calcium fly ash binder for kaolin clay soil stabilization: physicochemical evolution. Construction and building materials, 201,

$539-552$. https://doi.org/10.1016/j.conbuildmat.2018.12.188.

[3] Fatima Alsaleh, Feras Al Adday. 2020. Properties of Hot Mix Asphalt Containing Reclaimed Asphalt Pavement of the Aleppo highways. International Journal of Emerging Trends in Engineering Research. $\begin{array}{lllll}\text { Volume } & 8 . & \text { No. } & 8 & \text { August }\end{array}$ https://doi.org/10.30534/ijeter/2020/02882020.

[4] Vitale E., Russo G., Deneele D. (2020) Use of Alkali-Activated Fly Ashes for Soil Treatment. In: Calvetti F., Cotecchia F., Galli A., Jommi C. (eds) Geotechnical Research for Land Protection and Development. CNRIG 2019. Lecture Notes in Civil Engineering, vol 40. Springer, Cham. https://doi.org/10.1007/978-3-030-21359-6_77.

[5] Feras Al adday, Aymen Awad, 2020. A Review of the Status of Scientific Research and Practical Techniques Related to Using Cement Kiln Dust to Stabilize Weak Soils. International Journal of Advanced Trends in Computer Science and Engineering. Volume 9, No.4, July $\quad-\quad$ August 2020 https://doi.org/10.30534/ijatcse/2020/65942020.

[6] M. K. Soni and S. Singh, 2019. Statistical interpretation of marble dust and alccofine for soil stabilization. Int. J. Innov. Technol. Explor. Eng., vol. 8, no. 7, pp. 1609-1613, 2019.

[7] A. E. Eltwati, Tarhuni, 2020. Engineering properties of clayey soil stabilized with waste granite dust. J. Crit. Rev., vol. 7, no. 20, pp. 794-802, 2020

[8] Khalid Akbar Shah, 2020. A Study on Alluvial Soil Stabilization using Bitumen Emulsion. Int. J. Eng. Res., vol. V9, no. 06, pp. 229 239,2020

[9] Feras Al adday, 2020. Re-Evaluating Elements of an Existing MultiLevel Intersection Intersection: Na ur Interchange as a Case Study. International Journal of Engineering Research and Technology. ISSN 0974-3154, Volume 13, Number 8 (2020), pp. 1847-1853.
[10]K. Subba Rao. Soil stabililzation. Def. Sci. Organ. Minist. Defence, New Delhi. Def. Sci. J., vol. 2, no. 4, pp. 208-217, 1952.

[11]F. Sariosseiri and B. Muhuntha, 2009. Effect of cement treatment on geotechnical properties of some Washington State soils. Eng. Geol., 2009.

[12]M. H. Fasihnikoutalab, 2105. Olivine for Soil Stabilization. Pertanika J. Sch. Res. Rev., vol. 1, no. 1, pp. 18-26, 2015.

[13] S. S. Mohapatra and P. K, 2021. Pradhan. Review on Study of Soil Stabilization by Application of Microorganisms. Springer Singapore, 2021.

[14]P. Ghasemi, A. Zamani, and B. M. Montoya, Tri-Axial Behaviour of Steel Fiber-Reinforced Sand. Geo-Congress 2019, no. Hagen 1999, pp. 143-151, 2019.

[15]I. Chang, J. Im, and G. Cho, 2029. Introduction of Microbial Biopolymers in Soil Treatment for Future Environmentally-Friendly and Sustainable Geotechnical Engineering, 2016.

[16]M. A. Rahgozar, M. Saberian, and J. Li. Soil stabilization with nonconventional eco-friendly agricultural waste materials: An experimental study. Transp. Geotech., 2017.

[17]Kovtun, M., Ziolkowski, M., Shekhovtsova, J., \& Kearsley, E. (2016). Direct electric curing of alkali-activated fly ash concretes: a tool for wider utilization of fly ashes. Journal of Cleaner Production, 133, 220-227. https://doi.org/10.1016/i.jclepro.2016.05.098.

[18]A. B. Landage. Soil stabilization using soil isomorphism. No. August, 2014.

[19] Emmanuel, E., Paris, M., \& Deneele, D. (2019). Insights on the clay reactivity in alkaline media: Beyond filler role for kaolin. Applied Clay Science, 181. https://doi.org/10.1016/j.clay.2019.105210.

[20] Almalkawi, A. T., Balchandra, A., \& Soroushian, P. (2019). Potential of Using Industrial Wastes for Production of Geopolymer Binder as Green Construction Materials. Construction and Building Materials, 220, 516-524

[21]E. Adeyanju, C. A. Okeke, I. Akinwumi, and A. Busari, Subgrade Stabilization using Rice Husk Ash-based Geopolymer (GRHA) and Cement Kiln Dust (CKD). Case Stud. Constr. Mater., vol. 13, p. e00388, 2020.

[22]R. L. Parsons and J. P. Milburn, Engineering Behavior of Stabilized Soils. In Transportation Research Record, 2003.

[23]A. Kumar and A. Singh. Stabilization of expansive soil using cement kiln dust. Imp. J. Interdiscip. Res., vol. 6, no. 6, pp. 1089-1095, 2017.

[24]J. D. J. Arrieta Baldovino, R. L. Dos Santos Izzo, É. R. Da Silva, and J. Lundgren Rose. Sustainable Use of Recycled-Glass Powder in Soil Stabilization. J. Mater. Civ. Eng., vol. 32, no. 5, pp. 1-15, 2020.

[25]F. Sariosseiri and B. Muhuntha, 2009. Effect of cement treatment on geotechnical properties of some Washington State soils. Eng. Geol., 2009.

[26]Feras. Al Adday, 2020. Selecting the Best Method for Adding Recycled Aggregate. International Journal of Emerging Trends in Engineering Research vol. 8, no. 6, pp. 2253-2258, 2020. doi.org/10.30534/ijeter/2020/08862020

[27]M. A. Ahmmad al abo Hussien, 2019. Improving the Performance of Sub-grade of Asphalt Pavements Using Raw Materials Mill Dust of Cement Factories. J. Hama Univ., 2019.

[28] Ahmad Alabo Hussien, 2019. The Effect of the Return of Filters in Cement Factories ( The Dust) for Improving the Performance of Rely Soil and Asphalt Pavements. Thesis for master degree in department of Transport Engineering in faculty of Civil Engineering in Aleppo University.

[29]Aymen Awad, 2020. Guidelines for Civil Structures Demolition Method Selection to Enhance Environmental Protection International Journal of Emerging Trends in Engineering Research. Volume $\quad 8 . \quad$ No. $2, \quad$ February 2020 doi.org/10.30534/ijeter/2020/11822020.

[30] J. Sudheer Kumar and U. Janewoo, 2016. Stabilization of Expansive Soil with Cement Kiln Dust and RBI Grade 81 at Subgrade Level. Geotech. Geol. Eng., vol. 34, no. 4, pp. 1037-1046, 2016. 
[31]S. H. Bahmani, B. B. K. Huat, A. Asadi, and N. Farzadnia, Stabilization of residual soil using $\mathrm{SiO} 2$ nanoparticles and cement. Constr. Build. Mater., 2014.

[32]I. González Farias, W. Araujo, and G. Ruiz. Prediction of California Bearing Ratio from Index Properties of Soils Using Parametric and Non-parametric Models. Geotech. Geol. Eng., vol. 36, no. 6, pp. 3485-3498, 2018.

[33]Feras Al adday, Hadeel Mahasneh, Aymen Awad, Fatima Alsaleh, Nabil Elnaber, 2020. Sustainable pavement performance during freezing and variable immersion periods in water. International Journal of Advanced Trends in Computer Science and Engineering, 9(3), May - June 2020, 3410 - 3416 https://doi.org/10.30534/ijatcse/2020/142932020.

[34]N. C. Consoli, E. J. B. Marin, R. A. Q. Samaniego, K. S. Heineck, and A. D. R. Johann, 2019. Use of sustainable binders in soil stabilization. J. Mater. Civ. Eng., vol. 31, no. 2, 2019.

[35] aymen awad, feras al adday, altayeb qasem, ali al-dulaimy, 2020. An Experimental Study on the Possibility of Demolition of Destroyed Concrete Buildings with Different Types of Acid. International Journal of Engineering Research and Technology. ISSN 0974-3154, Volume 13, Number 9 (2020), pp. 2297-2304. 